\title{
PRODUCTS DERIVED FROM CATALYTIC OXIDATION OF METHYLENE BLUE
}

\author{
T. Lupaşcu*1, M. Ciobanu ${ }^{1}$, O. Bogdevici², V. Boțan ${ }^{1}$ \\ ${ }^{1}$ Institute of Chemistry of ASM, ${ }^{2}$ Institute of Geology and Seismology of ASM \\ Email: lupascu@gmail.com
}

\section{Introduction}

A large number of dyes have an important role not only in the textile and dye industries, but also in food, pharmaceuticals, cosmetics, and computers. These new applications bring a series of new problems in the purification of waste water obtained from different technological processes, because colorants are microtoxic, mutagens and carcinogens.

Obtaining of new catalysts, which would oxidize organic pollutants (dyes) in groundwater at relatively low temperatures represents an important goal in developing technologies for purification of wastewater obtained from various processes.

It is known that methylene blue in the presence of various catalysts (in most cases - modified adsorbents) and oxidants, undergoes transformations with the formation of new non-toxic products, whose structure has not yet been established [1-5].

The purpose of this paper is to study the oxidation products of methylene blue, using chromatography and mass spectrometry methods for this purpose.

\section{Results and discussions}

The process of oxidation of methylene blue was described in detail in our paper [6]. After 25 cycles of oxidation, the solution was separated from the active carbon CAN-8, subjected to vaporization in vacuum to $\mathrm{a} \sim 0.5 \mathrm{ml}$ volume. It was subsequently dried in the desiccator with phosphoric anhydride. The obtained content was analyzed using thin-layer chromatography. Two fragments were found in the oxidation products. To determine the structure of these fragments, a fresh aliquot of dye was subjected to oxidation, for 25 cycles, as well. After drying in the desiccator, the content was dissolved in methanol. The solution obtained after rinsing was subjected to liquid-liquid chromatographic and mass spectrometric analyses using Agilent 5973 mass spectrometer.

Figure 1 illustrates the chromatogram of products of catalytic oxidation of methylene blue and the table presents the retention time and their peaks areas.

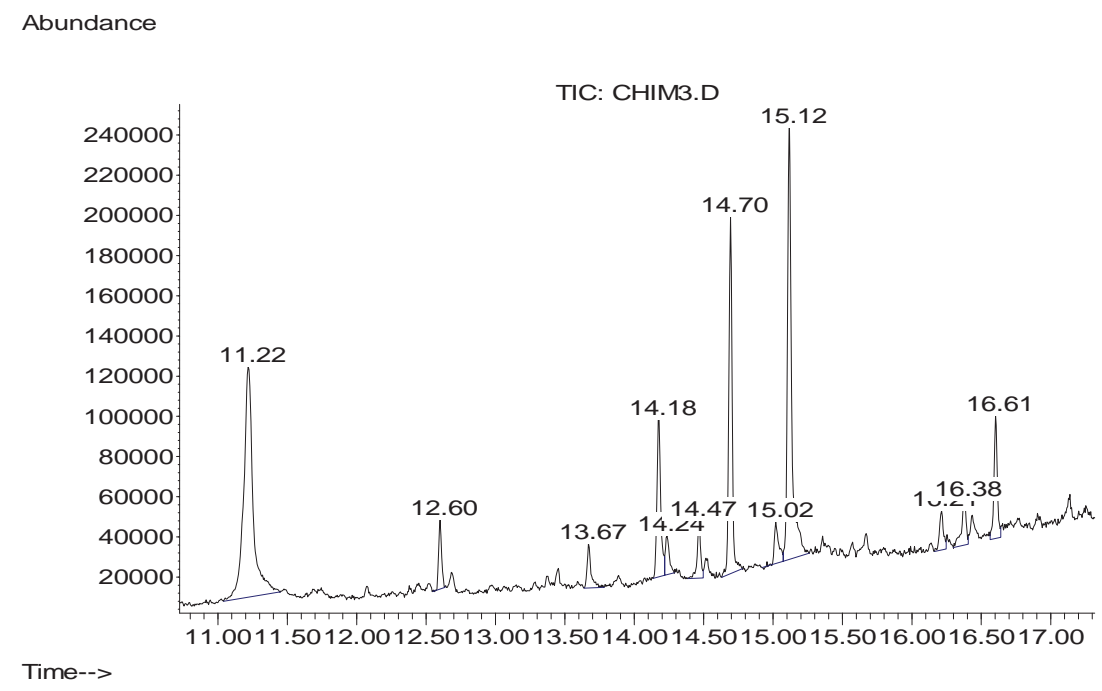

Fig.1. The chromatogram of products of catalytic oxidation of methylene blue 
Table 1

Retention time and peaks areas

\begin{tabular}{|c|c|c|}
\hline $\begin{array}{c}\text { Compound } \\
\#\end{array}$ & Retention time & Peak Area \\
\hline 1 & 11.222 & 5407038 \\
\hline 2 & 12.603 & 505822 \\
\hline 3 & 13.674 & 435750 \\
\hline 4 & 14.178 & 1486617 \\
\hline 5 & 14.237 & 382915 \\
\hline 6 & 14.469 & 488206 \\
\hline 7 & 14.696 & 2875073 \\
\hline 8 & 15.022 & 443141 \\
\hline 9 & 15.119 & 4577054 \\
\hline 10 & 16.215 & 376094 \\
\hline 11 & 16.378 & 512623 \\
\hline 12 & 16.606 & 1016222 \\
\hline
\end{tabular}

Figure 2 shows the diethyl phthalate mass spectrum (first peak) from the database.

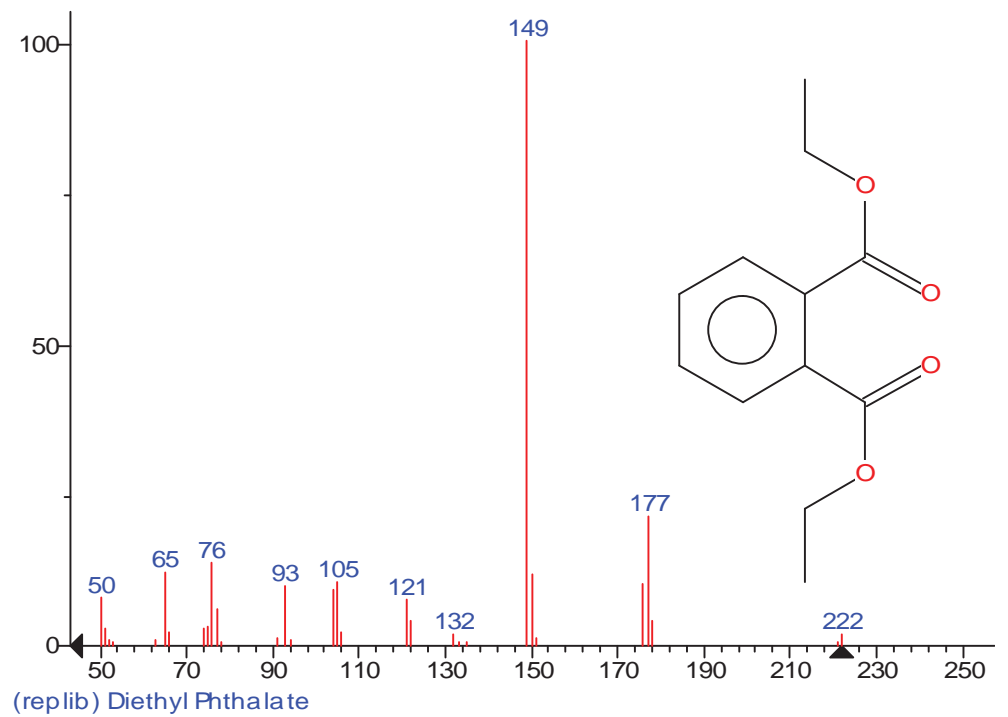

Fig.2. Mass spectrum of diethyl phthalate from the database.

Figure 3 shows diethyl phthalate mass spectrum from the database (a) and the first peak of the oxidation products (b), from figure 1.

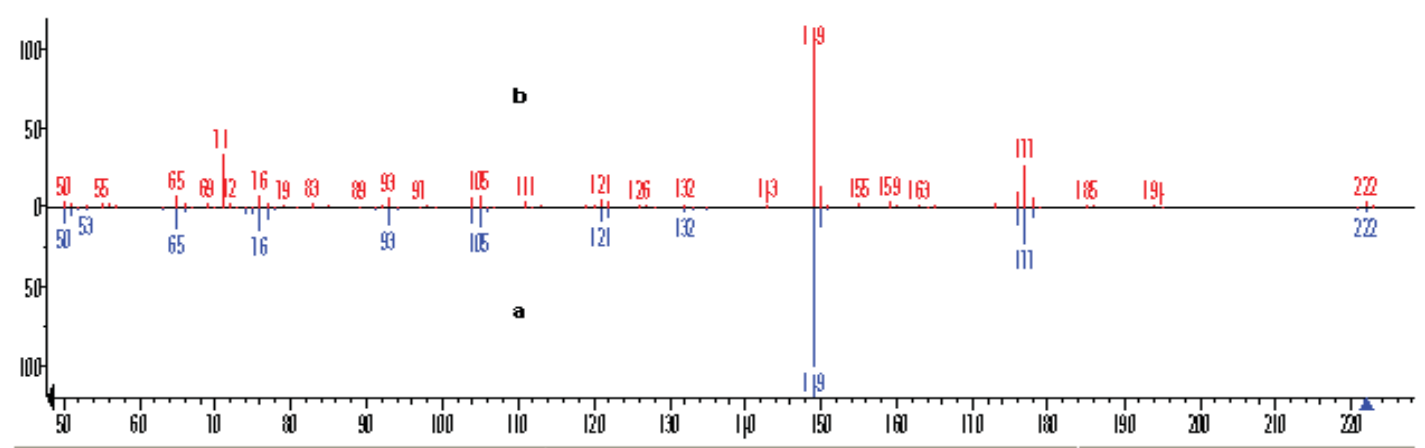

Figure 3. Diethyl phthalate mass spectrum from the database (a) and the first peak of the oxidation products (b).

From the presented data we find a coincidence of more than 90 percent of this substance.

The other peaks in the chromatogram presented in Figure 1 correspond to the retention time 12.6; 
$14.18 ; 14.47 ; 14.69 ; 15.12 ; 16.61$ and, respectively, to the following compounds: methyl tetradecanoate (97\%); 1,2-benzenedicarboxylic acid (83\%); 9-hexadecenoic acid (91\%); hexadecanoic acid (98\%); dibutyl phthalate (91\%); octadecanoic acid (99\%).

Analysis of obtained mass spectra show that the products obtained during the oxidation process, cannot form from the fragmentation of methylene blue, although a catalytic oxidation process of methylene blue is known, giving a series of products, such as butane-2 amine, arridinone, benzylidene, benzacetic acid, benzonitrile [7].

Much of the products obtained by us probably can get into the dry mixture from the vacuum distillation system, or from the methanol used as solvent. It is worth mentioning here that these products make up only $10 \%$ of methylene blue used during the 25 cycles. Proceeding from the structural formula of methylene blue (Fig. 4) in the oxidation process, the radical $\mathrm{OH}^{*}$, with very high oxidation potential $(2.8 \mathrm{v})$ opens the cycle containing nitrogen and sulfur atoms, so that nitrogen can oxidize to nitrates $\left(\mathrm{NO}_{3}{ }^{-}\right)$or free nitrogen and sulfur may oxidize to sulfates [8].<smiles>CN(C)c1ccc2nc3ccc(N(C)C)cc3[s+]c2c1</smiles>

Fig.4. Structure of methylene blue

The attack of $\mathrm{OH}^{\cdot}$ radical in the presence of oxygen initiates a complex cascade of oxidation reactions that lead to the mineralization of the resultant product. However, the precise directions of these reactions are not yet well defined. In any case, after the dissolution (after water vaporization) of oxidation products of methylene blue in methanol, an amount remains undissolved, which contains sulfates and nitrates, and which confirms the mineralization of methylene blue in the process of its oxidation.

The study of catalytic oxidation process with a different initial concentration of methylene blue $(120 \mathrm{mg} / \mathrm{L})$ produced an unexpected result. As a result there was a complete destruction of methylene blue. In this case the sample with oxidation products was subjected to vaporization in the drying oven at $100{ }^{\circ} \mathrm{C}$ and the dry content dissolved in very pure methanol.

The mechanism of this dye oxidation process is explained by participation of alkaline functional groups and by the fact that during oxygen bubbling through the solution containing methylene blue $\left(\mathrm{C}_{\mathrm{o}}=120 \mathrm{mg} / \mathrm{L}\right)$, on the surface of the activated carbon CAN-8 (at the interface) planar members (hemi-micelles) of dye and oxygen molecules are adsorbed. Thus, there is a potential difference at the interface and the $\mathrm{OH}^{*}$ radical is formed, which has a high oxidation potential $(2.8 \mathrm{~V})$, and which completely catalytically oxidizes methylene blue in the conditions of the experiment. In case of performing the process at a methylene blue concentration of $20 \mathrm{mg} / \mathrm{L}$, the $\mathrm{OH}^{\cdot}$ radical acts less effectively at the interface, due to the presence of a smaller number of dye molecules. Methylene blue adsorption occurs, in this case, from the real solutions, and not hemi-micellar ones.

In order to determine if any organic substances are eliminated from the studied active carbon during the oxidation process, we performed blank analysis.

Chromatograms of the zero sample are shown in figure 5 (activated carbon, demineralized water, bubbling with oxygen at $50{ }^{\circ} \mathrm{C}$ ) and of oxidation products of methylene blue $\mathrm{C}_{0}-120 \mathrm{mg} / \mathrm{L}$, activated carbon quantity CAN-8 - 200 $\mathrm{mg}$, Vsol.-100ml, bubbling with oxygen, p-2 atm, T-50 ${ }^{\circ} \mathrm{C}$.

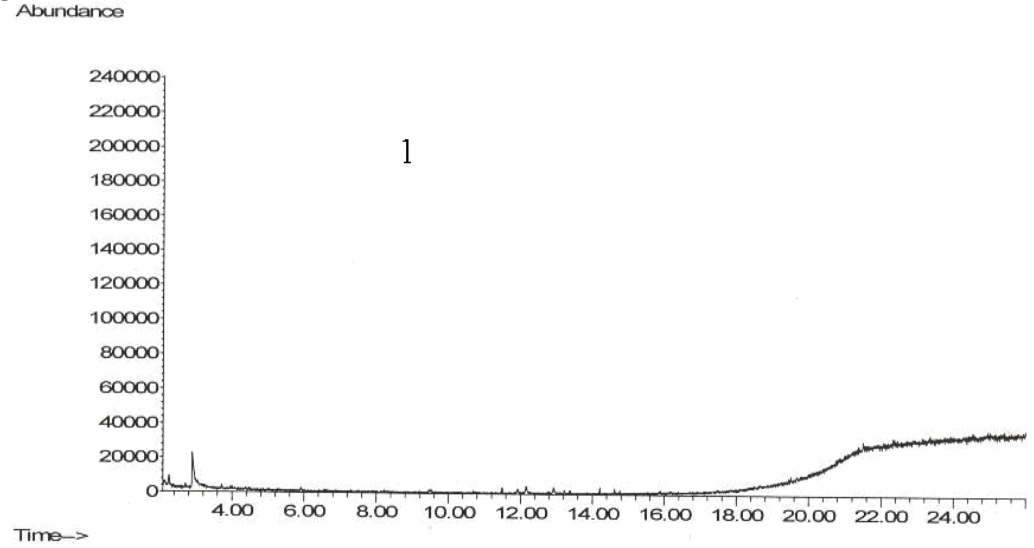




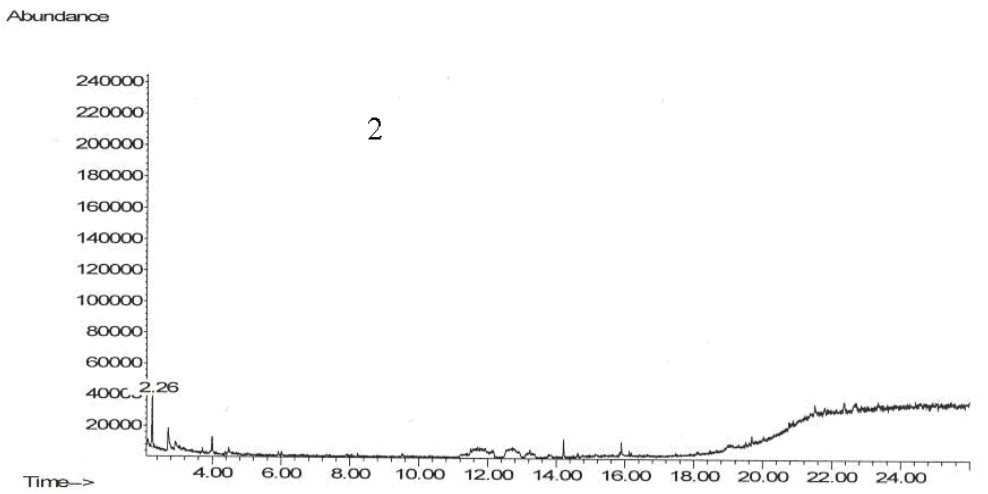

Fig. 5. Chromatogram of the blank sample (activated carbon, demineralized water, bubbling with oxygen at 50 ${ }^{0} \mathrm{C}$ ) (1) and chromatogram of oxidation products of methylene blue $\mathrm{C}_{0}-120 \mathrm{mg} / \mathrm{L}$, activated carbon quantity CAN-8 - $200 \mathrm{mg}$, Vsol.-100ml, bubbling with oxygen, p-2 atm, T-50 ${ }^{\circ} \mathrm{C}$. (2).

It should be noted that in paper [1], where the authors studied the oxidation of methylene blue using as the oxidant - tertiary-butyl hydroperoxide and as a catalyst - manganese oxide with different valences, at room temperature and higher temperatures, the products that are obtained as a result of oxidation are not named, although the mass spectra of obtained products were registered in time (kinetics of the process). Mass spectra for all times were totally different from those we obtained in the present work, which indicates that depending on the catalyst and oxidant studied, and on the concentration of the dye, different intermediate and final products are obtained.

\section{Conclusions}

1. It was established that the process of catalytic oxidation of methylene blue, at low concentrations $(20 \mathrm{mg} / \mathrm{L})$, i.e. in real solutions, gives sulfates and nitrates and new product, which can be categorized, in their vast majority, as impurities, probably got from the vacuum distillation unit, which make up for only $\sim 10 \%$ of methylene blue used in the experiment. Methylene blue adsorption at the interface occurs in real solutions.

2. In case of performing the process at methylene blue concentration of $120 \mathrm{mg} / \mathrm{L}$, hemi-micelles are adsorbed at the interface and the $\mathrm{OH}^{*}$ radical acts more effectively due to the presence at the interface of a greater number of dye molecules.

\section{References}

[1]. Thamayanthy Sriskandakumar, Naftali Openbe, Chun-Hu Chen, Almec Morey, Cecil King ondu and Steven L. Suib. J.Phys.Chem. A, 2009, 113(8), pp.1523-1530.

[2]. Maximov A.I., Subbotkina I.N., Hliustova A.V. Degradation of organic dyes in a diaphragm discharge in the volume of electrolyte. XXXV International Conference on Plasma Physics and Controlled Fusion, 11-15 February 2008 (in Russian).

[3]. H.S.Silva, N.D.Martinez, A.C.Deiana, J.E.Gonzalez. Catalytic oxidation of methylene blue in aqueous solutions. $-2^{\text {nd }}$ Mercosur Congress on Chemical Engineering. 2005, p.1-8.

[4]. Donaldson J.D.,Grimes S.M., Yasri N.G., Wheals B.: Parrick J; Errington W.E. Anodic oxidation of dye materials methylene blue, acid blue 25 , reactive blue 2 and reactive blue 15 and the characterisation of novel intermediate compounds in the anodic oxidation of methylene blue. - J. Chemical Tehnology and Biotechnology, v.77, Number 7, 2002,pp.756-760 (5).

[5]. Li J., Ma W., Huang Y., Cheng M., Zhao J., Yu J.C. A highly selective photooxidation approach using $\mathrm{O}_{2}$ in water catalyzed by iron (II) bipyridine complex supported on NaY zeolite. - Chem. Commun. 2003. 2214-2215.

[6]. Lupaşcu T., Ciobanu M., Boțan V., Nistor A. Oxidarea catalitică a albastrului de metilen.

[7]. Chemistry Journal of Moldova. 2010. v.5 No.2, p.37-40.

[8]. A. Rodriguez, G. Ovejero, M. Mestanza, V. Callejo, I. Garcia. Degradation of Methylene Blue by catalytic Wer Air Oxidation with Fe and $\mathrm{Cu}$ Catalyst Supported on Multiwalled Carbon Nanotubes.- Chemical Engineering Transactions V. 17, 2009, pp. 145-151.

[9]. Rein Munter. Advanced oxidation process - current status and prospects. - Proc. Estonian Acad. Sci. Chem., 2001, 50, 2, 59-80. 